\title{
African CDC needs more money and a strong leader
}

\section{Ebola spurred US support for pan-African health agency, but centre needs much more to succeed.}

\section{Declan Butler}

24 April 2015

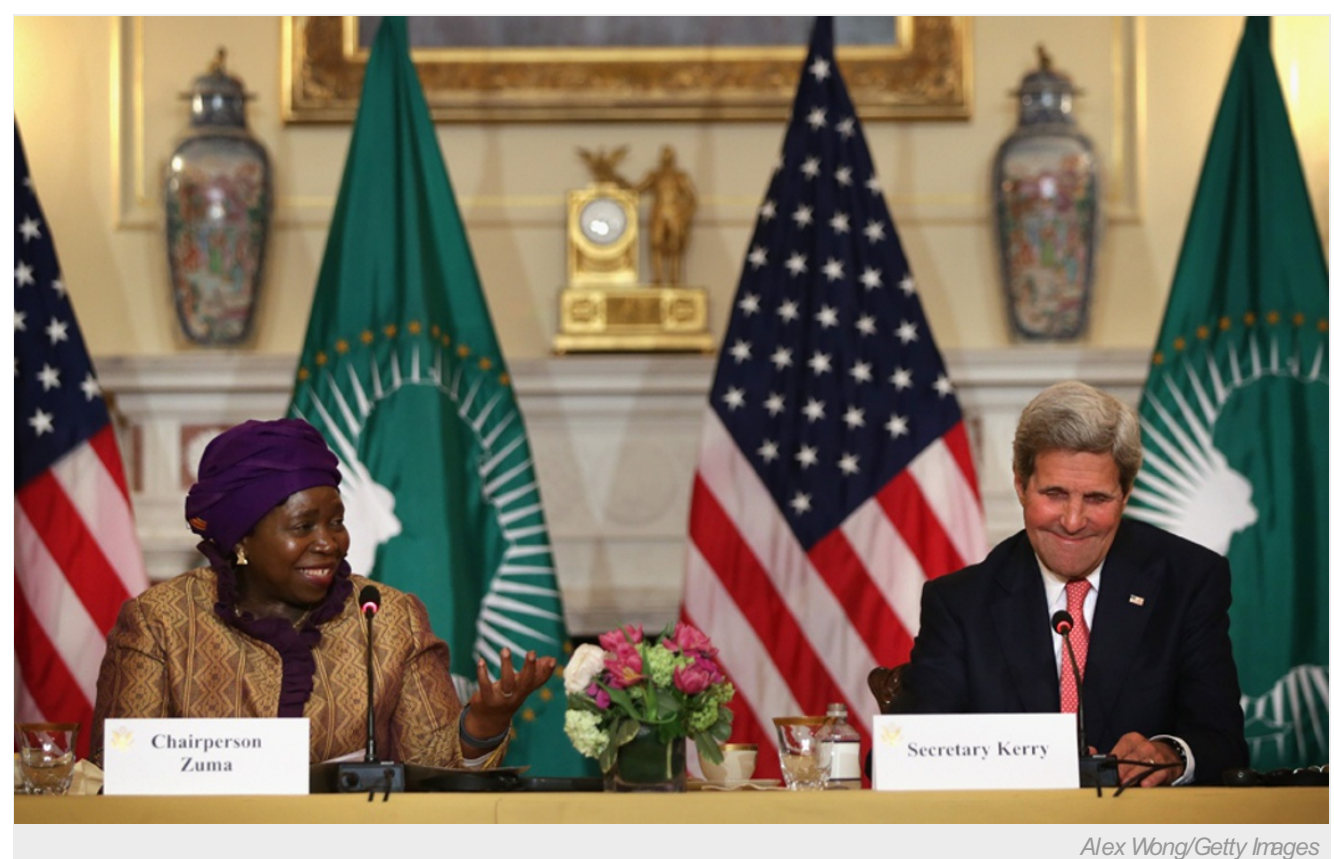

Nkosazana Dlamini-Zuma and John Kerry give the African CDC a major boost on 13 April.

A game-changer, or an excellent idea that will not get far? Plans for a pan-African public-health agency got a major boost last week. But although experts agree that the African Centres for Disease Control and Prevention (ACDC) has huge potential, they say that much more has to happen if it is to succeed.

The African Union (AU), which has 54 member countries, has had plans to create the ACDC since 2013. On 13 April, US Secretary of State John Kerry and Nkosazana Dlamini-Zuma, chair of the African Union Commission, announced that the preeminent US Centers for Disease Control and Prevention (CDC), based in Atlanta, Georgia, would provide the ACDC with technical expertise and advice. The Ebola epidemic in West Africa marked the "turning point" that prompted the AU to fast-track the centre, says Olawale Maiyegun, who is director of the commission's social-affairs department.

The ACDC is scheduled to open in June or July, initially at the AU headquarters in Addis Ababa. It would coordinate research throughout Africa on the biggest public-health threats, including diseases such as Ebola and meningitis. It would also act as a one-stop shop for data and reinforce countries' capacities for preventing epidemics and dealing with them — for example by creating a roster of experts and other professionals who could help to form a rapid-response force.

"I truly believe that the idea of an ACDC is a good one," says Solomon Nwaka, executive director of the African Network for Drugs and Diagnostics Innovation, also in Addis Ababa. "Africa needs more African-based and owned initiatives to tackle its health and developmental challenges." Microsoft founder Bill Gates, whose Bill \& Melinda Gates Foundation in Seattle, Washington, is a major funder of global health, tweeted this week that the ACDC could be a "game-changer".

\section{Budget questions}

The first reality check concerns money. The AU has budgeted just US\$6.9 million for its start-up phase from July 2015 to December 2016, and the centre would initially have just 11 staff members, far short of what is needed to operate a pan-African public-health agency, say experts. "If it is done right, it would be a marvellous thing," says Lawrence Gostin, a scholar of public-health law at Georgetown University in Washington DC. However, "the budget and staffing are entirely incommensurate with its goals". 
Maiyegun vigorously contests this, arguing that the ACDC does not need a large staff or budget to begin with, and that it will expand over time. But he declined to give estimates of future resources. This lack of a detailed financial programme disappoints many experts. "I would have liked to see a longer-term, at least five-year, forecast," says Nwaka.

Experts say that the bare minimum would be around 300 staff members, and a budget of about $\$ 60$ million. Those are the resources of the European Centre for Disease Prevention and Control (ECDC), based in Stockholm, on which the ACDC is modelled. Like the ECDC - and unlike the US CDC - the ACDC would have no in-house laboratories, but would act as a coordinator for its member states' national health-protection bodies and research labs.

Raising a budget on the order of the ECDC's would be difficult, because the AU itself has an annual budget of just $\$ 308$ million. The $\mathrm{AU}$ has set up a fund that will seek contributions from its member states and the private sector in Africa, says Maiyegun. Last year, it also created a multinational task-force - made up of representatives from African states, the US CDC, the Chinese CDC and international groups such as the World Health Organization and UN children's fund UNICEF — to seek further funding and international technical support.

\section{Expert networks}

The US CDC will locate two experts in Addis Ababa to act as long-term technical advisers, and it will fund fellowships for ten African epidemiologists, says Tom Kenyon, director of the US agency's Center for Global Health. Other public-health agencies outside Africa are expected to follow suit, although Maiyegun declined to give details.

Building strong partnerships with existing research and public-health bodies would be the best way to get the ACDC up and running quickly, says Nwaka. Marc Sprenger, director of the ECDC, notes that links with national health powerhouses and leading research labs such as the Robert Koch Institute in Berlin and Public Health England in London are key to his organization's success. Africa's public-health infrastructure is much weaker than Europe's, but there are many good public-health labs that could be tapped, he says.

\section{Strong leadership}

A nagging concern is that the ACDC may become mired within the AU, which is often criticized for being ineffective, bureaucratic and highly politicized. "The leadership of the ACDC has to be sufficiently empowered and resourced, with necessary flexibility to be able to deliver, otherwise we are back to square one," says Nwaka.

The AU is currently seeking a director for the ACDC. However, the international civil-servant salary grade listed with the job is below that typically offered for such a senior position, according to one expert, which will make it difficult to attract high-calibre candidates.

Inevitable teething problems and valid concerns must not be allowed to obscure the bigger picture — that the ACDC represents a major, and welcome, shift in Africa's approach to public-health emergencies, says David Fidler, who studies international law and global health at Indiana University Bloomington. "It reflects African states, acting through the AU, taking more responsibility for postEbola health security in Africa," he says. Or, as Maiyegun puts it: "Africa is prepared to take its health into its own hands."

Nature | doi:10.1038/nature.2015.17409 